Article

\title{
Comparison of Perioperative Chemotherapy versus Postoperative Chemoradiotherapy for Operable Stomach Cancer: A Western Canadian Province Experience
}

\author{
Adnan Zaidi ${ }^{1}$, Amal Khan ${ }^{2}$, Claire Duval ${ }^{2}$, Kamal Haider ${ }^{1}$, Osama Ahmed ${ }^{1}$, Dorie-Anna Dueck ${ }^{1}$, \\ Bryan Brunet ${ }^{1}$, Donald Gardiner ${ }^{1}$ and Shahid Ahmed ${ }^{1, *}$ \\ 1 Saskatoon Cancer Center, Saskatchewan Cancer Agency, University of Saskatchewan, \\ Saskatoon, SK S7N4H4, Canada; adnan.zaidi@saskcancer.ca (A.Z.); kamal.haider@saskcancer.ca (K.H.); \\ osama.ahmed@saskcancer.ca (O.A.); dorie-anna.dueck@saskcancer.ca (D.-A.D.); \\ bryan.brunet@saskcancer.ca (B.B.); donald.gardiner@saskcancer.ca (D.G.) \\ 2 College of Medicine, University of Saskatchewan, Saskatoon, SK S7N4H4, Canada; \\ amal.khan@usask.ca (A.K.); claire.duval@usask.ca (C.D.) \\ * Correspondence: shahid.ahmed@saskcancer.ca; Tel.: +1-306-655-2710
}

Citation: Zaidi, A.; Khan, A.; Duval, C.; Haider, K.; Ahmed, O.; Dueck, D.-A.; Brunet, B.; Gardiner, D.; Ahmed, S. Comparison of Perioperative Chemotherapy versus Postoperative Chemoradiotherapy for Operable Stomach Cancer: A Western Canadian Province Experience. Curr. Oncol. 2021, 28, 1262-1273. https:// doi.org/10.3390/curroncol28020120

Received: 1 February 2021

Accepted: 12 March 2021

Published: 17 March 2021

Publisher's Note: MDPI stays neutral with regard to jurisdictional claims in published maps and institutional affiliations.

Copyright: () 2021 by the authors. Licensee MDPI, Basel, Switzerland. This article is an open access article distributed under the terms and conditions of the Creative Commons Attribution (CC BY) license (https:// creativecommons.org/licenses/by/ $4.0 /)$.

\begin{abstract}
Background: The standard approaches for resectable stomach cancer are postoperative chemoradiotherapy (PCR) or perioperative chemotherapy (PC). Limited evidence is available regarding the superiority of one of the two approaches. We aimed to compare the survival of patients with operable stomach cancer who were treated with PC or PCR. Methods: In this retrospective cohort study, patients with operable stomach cancer diagnosed between 2005-2015 in the province of Saskatchewan were identified and, based on type of treatment, were placed into PCR and PC groups. A Cox proportional multivariate analysis was performed to assess independent prognostic variables, including survival advantage of PC over PCR. Results: A total of 88 eligible patients with a median age of 66 (56-71) and a male to female ratio of 1:0.44 were identified. Seventy-three (83\%) patients had pathologically node positive disease. Sixty-seven $(76 \%)$ patients received PCR, while 21 (24\%) patients received PC. The median overall survival of the whole group was 34 months, with 38 months (95\% CI 24.6-51.3) in the PCR group vs. 30 months (14.3-45.7) in the PC group ( $p=0.29)$. Median relapse-free survival was 34 months (20.7-47.3) in the PCR group vs. 23 months (6.7-39.3) in the PC group $(p=0.20)$. Toxicities were comparable. On multivariate analysis, $\mathrm{T} \geq 3$ tumor $(\mathrm{HR}, 3.57$ (1.39-8.56)), neutrophil to lymphocyte ratio (LNR) > 2.8 (HR, 1.85 (1.05-3.25)), and positive resection margins (HR, 1.89 (1.06-3.37)) were independently correlated with inferior survival. Conclusions: This well-designed population based cohort study suggests a lack of survival benefit of PC over PCR. Both treatment options remain viable approaches for resectable stomach cancer.
\end{abstract}

Keywords: stomach cancer; perioperative chemotherapy; postoperative chemoradiotherapy; neutrophil to lymphocyte ratio

\section{Introduction}

Stomach cancer remains one of the most common forms of cancer worldwide, accounting for about $9.9 \%$ of new cancers [1,2]. It represents the second leading cause of cancer death worldwide and is the fourth most common malignancy in the world [3]. Surgery is the main curative therapy; nevertheless, substantial numbers of patients with localized cancer develop recurrence following curative surgery alone. The 5-year survival rate for surgically resected stage IIB disease is below 35\% and even lower for more advanced-stage disease [1,2]. Recurrence after surgery is usually incurable and efforts have been made to improve survival by the addition of adjuvant or neoadjuvant therapy. Some of the relatively modern trials involve the use of adjuvant or perioperative therapy. The landmark U.S. Intergroup (INT-0116) study and the United Kingdom Medical Council Adjuvant Gastric 
Infusional Chemotherapy (MAGIC) trials demonstrated that adjuvant chemoradiotherapy or perioperative chemotherapy (PC) decreases the relapse rate and improves the survival of patients with stomach cancer, respectively [4,5].

The INT-0116 study (adjuvant chemoradiation therapy versus observation after curative gastric cancer resection) was first reported in 2001. It randomized a total of 556 patients with stage IB to IVM0 operable stomach and gastroesophageal (GE) junction cancers to postoperative adjuvant chemotherapy vs. surgery alone. The postoperative adjuvant group had a median overall survival (OS) of 36 months compared to 27 months in the surgery only group (hazard ratio (HR) for death, 1.35 [95\% confidence interval (CI), 1.09 to 1.66; $p=0.005]$ [ [4]. This trial established postoperative chemoradiotherapy (PCR) as a standard approach for completely resected stage IB to IVM0 gastric and GE junction cancer. This approach was widely adopted in North America.

In 2006, the MAGIC (Preoperative chemotherapy versus surgery alone for resectable gastroesophageal cancer) trial by the Medical Research Council in the UK was reported. This trial enrolled 503 patients with resectable stomach (74\%), distal esophageal, or GE junction adenocarcinoma who were randomly assigned to surgery alone or surgery plus PC (three preoperative and three postoperative cycles of epirubicin, cisplatin and 5-flurouracil). When compared with the surgery group, the PC group had a higher likelihood of OS (HR, $0.75 ; 95 \%$ CI, 0.60 to $0.93 ; p=0.009$; 5 -year survival rate, $36 \%$ vs. $23 \%$ ) and of progressionfree survival (HR, $0.66 ; 95 \%$ CI, 0.53 to $0.81 ; p<0.001$ ) [5]. Because of the results of this trial, PC also became a standard of care and was widely adopted in Europe.

These two trials have established either PCR or PC as standard adjuvant therapy for operable stomach cancer. Several other studies have evaluated preoperative chemotherapy with variable results [6-8]. A meta-analysis of 12 trials involving 1820 patients that evaluated various preoperative chemotherapy regimens with surgery alone concluded that preoperative chemotherapy was associated with significant improvement in both disease-free survival (odd ratio (OR) 1.85, 95\% CI 1.39-2.46) and OS (OR 1.32, 95\% CI 1.07-1.64) [9]. Likewise, several randomized trials investigated various postoperative chemotherapy regimens with or without radiation with inconsistent results [10-14]. An individual patient data meta-analysis from 17 trials involving 3838 patients with a median follow-up exceeding seven years demonstrated that adjuvant chemotherapy was associated with a significant benefit in terms of OS (HR, 0.82; 95\% CI, 0.76-0.90; $p<0.001)$ and diseasefree survival (HR, 0.82; 95\% CI, 0.75-0.90; $p<0.001)$ [15]. Another meta-analysis of six randomized controlled trials involving 1171 patients compared adjuvant chemoradiotherapy to chemotherapy [16]. While chemoradiotherapy was associated with a significantly better disease-free survival rate (OR 1.56, 95\% CI 1.09-2.24), the survival benefit was not significant (OR 1.32, 95\% CI 0.92-1.99). A recent study using U.S. databases suggests that neoadjuvant and perioperative chemotherapy may confer a survival advantage over postoperative treatment [17]; the results have not been confirmed by other studies.

Taken together, it is not known whether the two standard approaches in the management of operable stomach cancer are comparable or if one approach is more effective than the other. There are no randomized trials comparing the two approaches. Moreover, there is limited knowledge about the effectiveness of these two strategies in real-world patients. Despite this, the current trends have led to a greater adoption of PC, especially since the publication of the FLOT (fluorouracil plus leucovorin, oxaliplatin and docetaxel)-4 study [18].

The aim of the current study was to compare the survival of patients with operable stomach cancer who were treated with either PC or PCR as standard adjuvant therapy in Saskatchewan and to determine factors that correlated with survival. We hypothesize that PC improves the outcomes of real-world patients with operable stomach cancer compared to PCR. We also aimed to identify factors that correlated with survival in patients with operable stomach cancer. 


\section{Methods}

This was a retrospective population-based cohort study. The study population was comprised of patients with operable stomach cancer diagnosed between January 2005 and December 2015 in the province of Saskatchewan, Canada. International Classification of Disease (ICD) codes relevant for stomach and GE junction cancers were used to identify eligible patients using the Saskatchewan Cancer Registry. Patients with other histological diagnoses, including lymphoma, neuroendocrine tumor, small cell cancer, melanoma and hepatocellular cancer, or with another active secondary malignancy, were excluded. In addition, patients who were treated with preoperative chemoradiotherapy or adjuvant chemotherapy alone were excluded. A pre-specified abstraction sheet was used for data collection. Clinical stage was based on baseline staging imaging scans. All medical records were reviewed and abstracted by a trained research associate. Due to the retrospective nature of the data, only moderate to severe toxicities documented in the health records of patients were recorded.

Based on type of treatment patients were divided into two groups - those who received PC and those who received PCR. PC was mostly comprised of combination chemotherapy that was administered for three cycles preoperatively and three cycles postoperatively. Each 3-week cycle consisted of epirubicin $\left(50 \mathrm{mg} / \mathrm{m}^{2}\right)$ by intravenous bolus on day 1 , cisplatin $\left(60 \mathrm{mg} / \mathrm{m}^{2}\right)$ or oxaliplatin $\left(130 \mathrm{mg} / \mathrm{m}^{2}\right)$ intravenously with hydration on day 1 , and fluorouracil $\left(200 \mathrm{mg} / \mathrm{m}^{2}\right)$ daily for 21 days by continuous intravenous infusion or capecitabine $625 \mathrm{mg} / \mathrm{m} 2 /$ day per oral twice per day (PO BID). PCR was comprised of one cycle of FU (425 mg/m² per day) and leucovorin $\left(20 \mathrm{mg} / \mathrm{m}^{2}\right.$ per day) daily for five days then one month later $45 \mathrm{~Gy}$ (1.8 Gy per day) of radiation with FU $\left(400 \mathrm{mg} / \mathrm{m}^{2}\right.$ per day) and leucovorin (20 mg/m² per day) on days 1 through 4 and on the last three days of RT or capecitabine ( $825 \mathrm{mg} / \mathrm{m}^{2}$ PO BID) continuously during radiation. One month after completion of radiation two more five-day cycles of chemotherapy (FU) $425 \mathrm{mg} / \mathrm{m}^{2}$ per day and leucovorin $20 \mathrm{mg} / \mathrm{m}^{2}$ per day) were given at monthly intervals.

During the study period both PC and PCR were accepted standard of care treatments. Not all cases were reviewed at a multidisciplinary tumor round. Based on various patients and tumor related factors such as age, underlying cardiovascular disease, or major bleeding, PC or PCR was selected by the treating physicians. All patients who were diagnosed with stomach cancer in Saskatchewan were seen at the two major cancer centers. Patients were followed up at the cancer center after completion of treatment and those who were in remission were subsequently discharged to their primary care physicians. Patients who developed recurrent disease were reassessed for palliative therapy. Survival data was collected from patient's medical records and the Saskatchewan Cancer Registry.

\section{Analysis of Primary and Secondary Endpoints}

The survivals of the entire cohort and subgroups were estimated by using the KaplanMeier method. The survival distribution of different groups was compared by the log rank test. Cox proportional multivariate analysis was performed to determine the prognostic significance of second-line therapy. The HR and its 95\% CI were estimated. The following variables were examined with respect to their prognostic significance: age (<65 vs. $\geq 65$ ); gender; major comorbid illness per the Charlson Comorbidity Index; World Health Organization (WHO) performance status ( $<1$ vs. $\geq 1$ ); marital status (married or common-law partners vs. single or widowed); children; residence (urban vs. rural); smoking status; cancer center; treatment type (perioperative vs. postoperative chemoradiotherapy); median neutrophil to lymphocyte ratio (NLR); residence; node status (node positive vs. node negative); stage; time period (2005-2010 vs. 2011-2015); and grade (3 or 1 and 2).

All variables with $p<0.05$ on univariate analysis or which were biologically important were examined in a multivariate model to assess their correlation with survival. The likelihood ratio test and $t$-test were used to determine whether the addition of independent variables of interest significantly added to the prediction of survival in the model. Tests for 
interaction and confounding factors were assessed for important variables. All $p$-values were two-sided. A $p$-value of $<0.05$ was considered statistically significant.

\section{Results}

Using ICD codes, a total of 345 patients with stomach and GE junction cancers who were diagnosed in Saskatchewan during the study period were identified. Of 345 patients, only 88 patients were found to fulfill eligibility criteria (Figure 1). Most patients were excluded because of metastatic disease, poor performance status, or major active comorbid illnesses, were not candidates for surgery or chemotherapy, or declined standard treatment. In addition, patients with GE junction cancer who were treated with preoperative chemoradiotherapy or those who received postoperative chemotherapy alone were excluded. Of 88 patients, 67 patients received PCR and 21 patients received PC. ECF (epirubicin, cisplatin and infusional $5 \mathrm{FU}$ ) was the most common regimen and was used in $62 \%$ patients followed by EOF (epirubicin, oxaliplatin and infusional 5FU). Only one patient received the FLOT (5FU, oxaliplatin and docetaxel) regimen. Patients' baseline characteristics are described in Table 1. Despite small numbers, the two groups were relatively well-balanced. The median age of the entire cohort was 63 years. The majority of the patients were men. Most patients had an WHO performance status of 0 or $1,97 \%$ for the PCR group and $100 \%$ for the PC group. Most patients had clinical stage I or II cancer, $92 \%$ in the PCR group and $85 \%$ in the PC group. Post-surgery with or without preoperative chemotherapy pathological stage III was $52 \%$ for the entire cohort, $55 \%$ in the PCR group vs. $43 \%$ in the PC group. About two-thirds of patients had grade 3 tumors.

Table 1. Characteristics of patients who received adjuvant chemoradiotherapy versus perioperative chemotherapy.

\begin{tabular}{|c|c|c|c|c|}
\hline Variables & $\begin{array}{l}\text { All Patients } \\
N=88(\%)\end{array}$ & $\begin{array}{c}\text { Adjuvant } \\
\text { Chemoradiotherapy Group } \\
\mathrm{N}=67(\%)\end{array}$ & $\begin{array}{c}\text { Peri-Operative } \\
\text { Chemotherapy Group } \\
\mathrm{N}=21(\%)\end{array}$ & $p$ Value \\
\hline Median Age & 63 (IQR: 56-71) & 63 (IQR: 56-73) & 61 (IQR: 52-70) & 0.41 \\
\hline Men & $61(69)$ & $48(72)$ & $13(62)$ & 0.42 \\
\hline Comorbid illness & $51(58)$ & $40(60)$ & $11(52)$ & 0.61 \\
\hline \multicolumn{5}{|l|}{ WHO Performance Status } \\
\hline 0 & $27(31)$ & $20(30)$ & $7(33)$ & 0.79 \\
\hline 1 & $59(67)$ & $45(67)$ & $14(67)$ & 1.0 \\
\hline 2 & $2(2)$ & $2(3)$ & 0 & 1.0 \\
\hline Current Smoker & $18(21)$ & $13(19)$ & $5(24)$ & 0.75 \\
\hline Past Smoker & $42(48)$ & $34(51)$ & $8(38)$ & 0.33 \\
\hline Secondary Cancer & $12(14)$ & $10(15)$ & $2(10)$ & 0.72 \\
\hline \multicolumn{5}{|l|}{ Clinical Stage } \\
\hline I & $33(38)$ & $26(38)$ & $7(33)$ & 0.80 \\
\hline II & $47(53)$ & $36(54)$ & $11(52)$ & 1.0 \\
\hline III & $6(7)$ & $3(5)$ & $3(15)$ & 0.14 \\
\hline Not known & $2(2)$ & $2(3)$ & 0 & \\
\hline \multicolumn{5}{|l|}{ Site } \\
\hline $\begin{array}{l}\text { Gastroesophageal (GE) } \\
\text { Junction/cardia }\end{array}$ & $41(47)$ & $33(49)$ & $8(38)$ & 0.45 \\
\hline Body & $8(9)$ & $4(6)$ & $4(19)$ & 0.08 \\
\hline
\end{tabular}


Table 1. Cont.

\begin{tabular}{|c|c|c|c|c|}
\hline Variables & $\begin{array}{l}\text { All Patients } \\
\mathrm{N}=88(\%)\end{array}$ & $\begin{array}{c}\text { Adjuvant } \\
\text { Chemoradiotherapy Group } \\
\mathrm{N}=67(\%)\end{array}$ & $\begin{array}{c}\text { Peri-Operative } \\
\text { Chemotherapy Group } \\
\mathrm{N}=21(\%)\end{array}$ & $p$ Value \\
\hline Antrum/Pylorus & $39(44)$ & $30(45)$ & $9(43)$ & 1.0 \\
\hline Clinical node positive & $36(41)$ & $25(37)$ & $11(52)$ & 0.20 \\
\hline Pathological node positive & $73(83)$ & $58(87)$ & $15(71)$ & 0.18 \\
\hline \multicolumn{5}{|l|}{ Pathological Stage } \\
\hline 0 & $1(1)$ & 0 & $1(5)$ & 0.23 \\
\hline I & $5(6)$ & $2(3)$ & $3(14)$ & 0.08 \\
\hline II & $36(41)$ & $28(42)$ & $8(38)$ & 0.80 \\
\hline III & $46(52)$ & $37(55)$ & $9(43)$ & 0.45 \\
\hline Positive margin & $21(24)$ & $17(25)$ & $4(19)$ & 0.77 \\
\hline Grade $\geq 3$ & $56(64)$ & $42(63)$ & $14(67)$ & 0.80 \\
\hline $\begin{array}{l}\text { Mean white blood cell } \\
\text { (WBC) }\end{array}$ & $7.7 \pm 2.5$ & $7.7 \pm 2.7$ & $7.9 \pm 2.1$ & 0.68 \\
\hline Mean Hemoglobin & $123 \pm 19$ & $123 \pm 17$ & $125 \pm 26$ & 0.52 \\
\hline Mean Platelets & $300 \pm 102$ & $310 \pm 102$ & $271 \pm 97$ & 0.12 \\
\hline Mean Creatinine & $75 \pm 21$ & $76 \pm 23$ & $75 \pm 17$ & 0.91 \\
\hline Mean Albumin & $35 \pm 5$ & $35 \pm 5$ & $35 \pm 5$ & 0.81 \\
\hline Mean Bilirubin & $9.1 \pm 5.6$ & $9.4 \pm 5.9$ & $8.5 \pm 4.5$ & 0.54 \\
\hline $\begin{array}{l}\text { Mean Alkaline } \\
\text { Phosphatase }\end{array}$ & $84 \pm 36$ & $81 \pm 23$ & $93 \pm 65$ & 0.22 \\
\hline $\begin{array}{c}\text { Mean Alanine } \\
\text { aminotransferase (ALT) }\end{array}$ & $23 \pm 35$ & $23 \pm 39$ & $23 \pm 14$ & 0.98 \\
\hline $\begin{array}{c}\text { Mean carcinoembryonic } \\
\text { antigen (CEA) }\end{array}$ & $1.8 \pm 1.1$ & $1.8 \pm 1.1$ & $1.6 \pm 1.2$ & 0.63 \\
\hline
\end{tabular}

The OS for the entire group was 34 months (95\% CI 23-45), 38 months (24.6-51.3) in the PCR group vs. 30 months (14.3-45.7) in the PC group $(p=0.29)$ (Figure 2A, Table 2). The median relapse-free survival was 34 months for the PCR group and 23 months for the PC group ( $p=0.20$ ) (Figure 2B). At 5 years, 31\% of patients were relapse-free (33\% in the PCR group vs. $29 \%$ in the PC group) and $34 \%$ of patients were alive (39\% in the PCR group vs. $29 \%$ in the PC group).

Table 2. Outcome of patients with early stage stomach and GE junction cancers who received adjuvant chemoradiotherapy versus perioperative chemotherapy.

\begin{tabular}{|c|c|c|c|c|}
\hline Variables & $\begin{array}{l}\text { All Patients } \\
\mathrm{N}=88(\%)\end{array}$ & $\begin{array}{c}\text { Adjuvant } \\
\text { Chemoradiotherapy Group } \\
\mathrm{N}=67(\%)\end{array}$ & $\begin{array}{c}\text { Peri-Operative } \\
\text { Chemotherapy Group } \\
\mathrm{N}=\mathbf{2 1}(\%)\end{array}$ & $p$ Value \\
\hline Median RFS months (95\% CI) & $32(21.3-42.7)$ & $34(20.7-47.3)$ & $23(6.7-39.3)$ & NS \\
\hline Median OS months (95\% CI) & $34(23-45)$ & $38(24.6-51.4)$ & $30(14.3-45.7)$ & NS \\
\hline Three year-RFS & $49 \%$ & $55 \%$ & $43 \%$ & NS \\
\hline Five year-RFS & $31 \%$ & $33 \%$ & $29 \%$ & NS \\
\hline Three year-OS & $52 \%$ & $55 \%$ & $48 \%$ & NS \\
\hline Five year-OS & $34 \%$ & $39 \%$ & $29 \%$ & NS \\
\hline
\end{tabular}

CI: confidence interval; NS: not significance; OS: overall survival; RFS: Recurrence-free survival. 


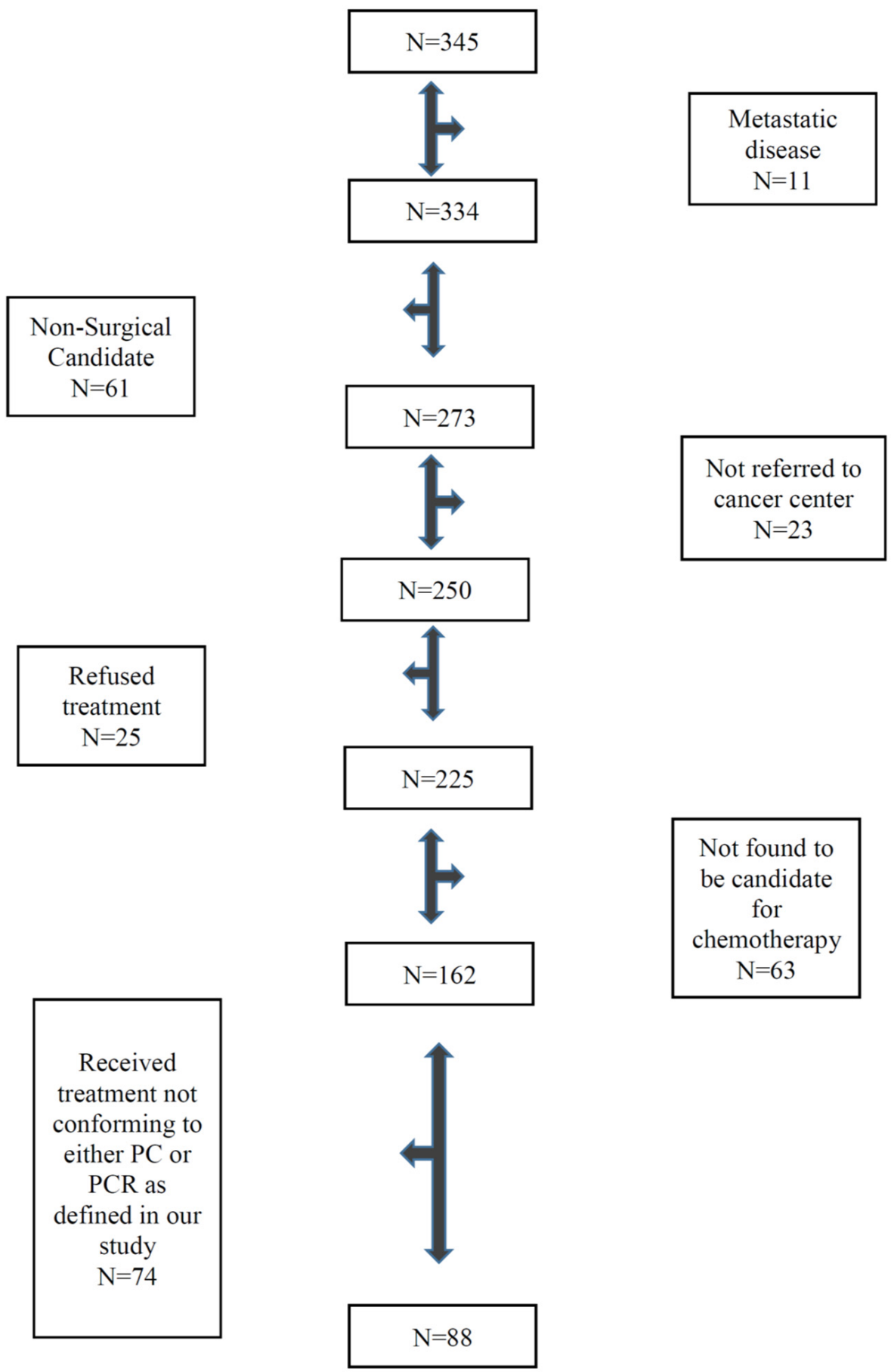

Figure 1. Flow chart showing eligible patients. 


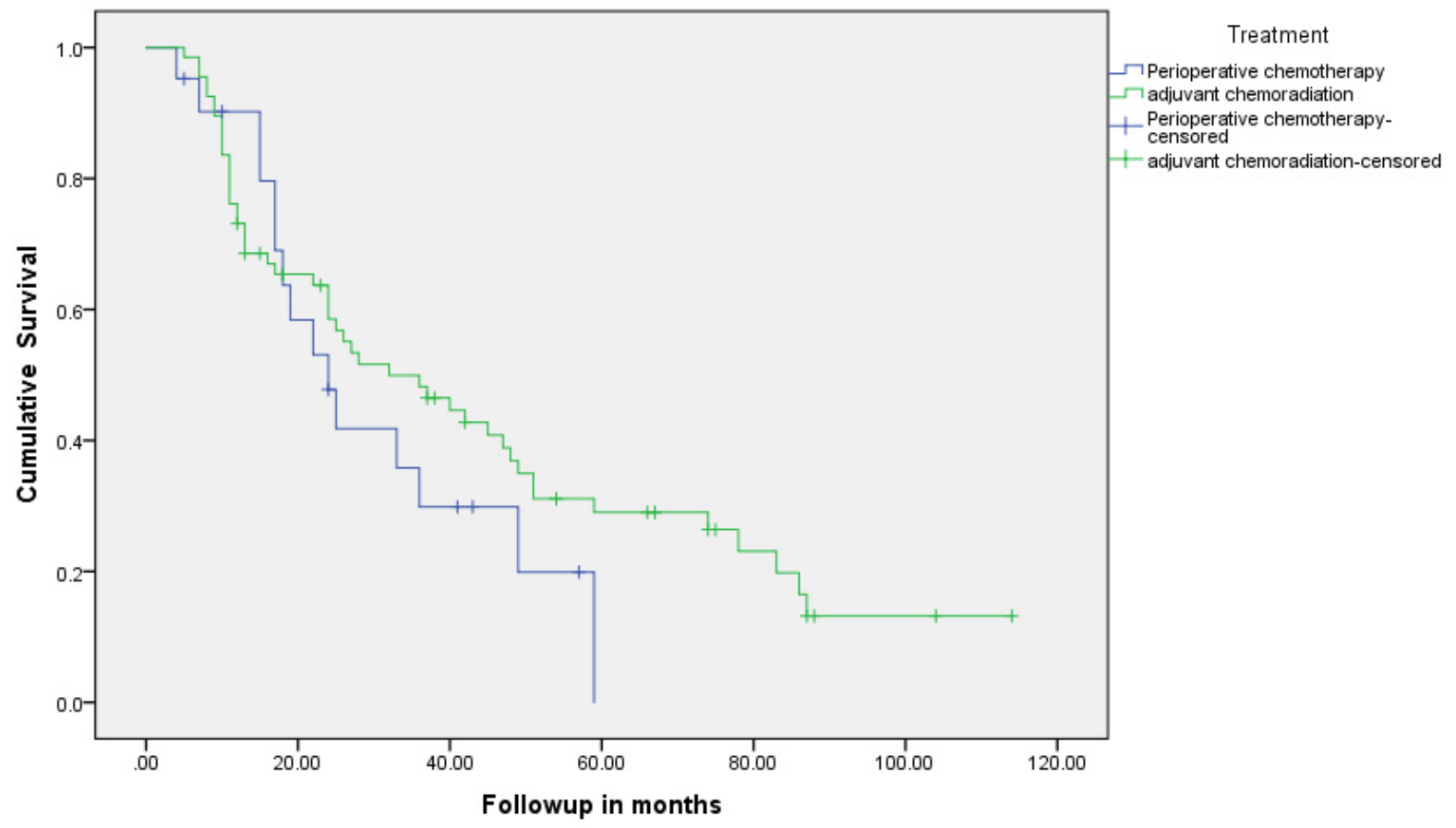

(A)

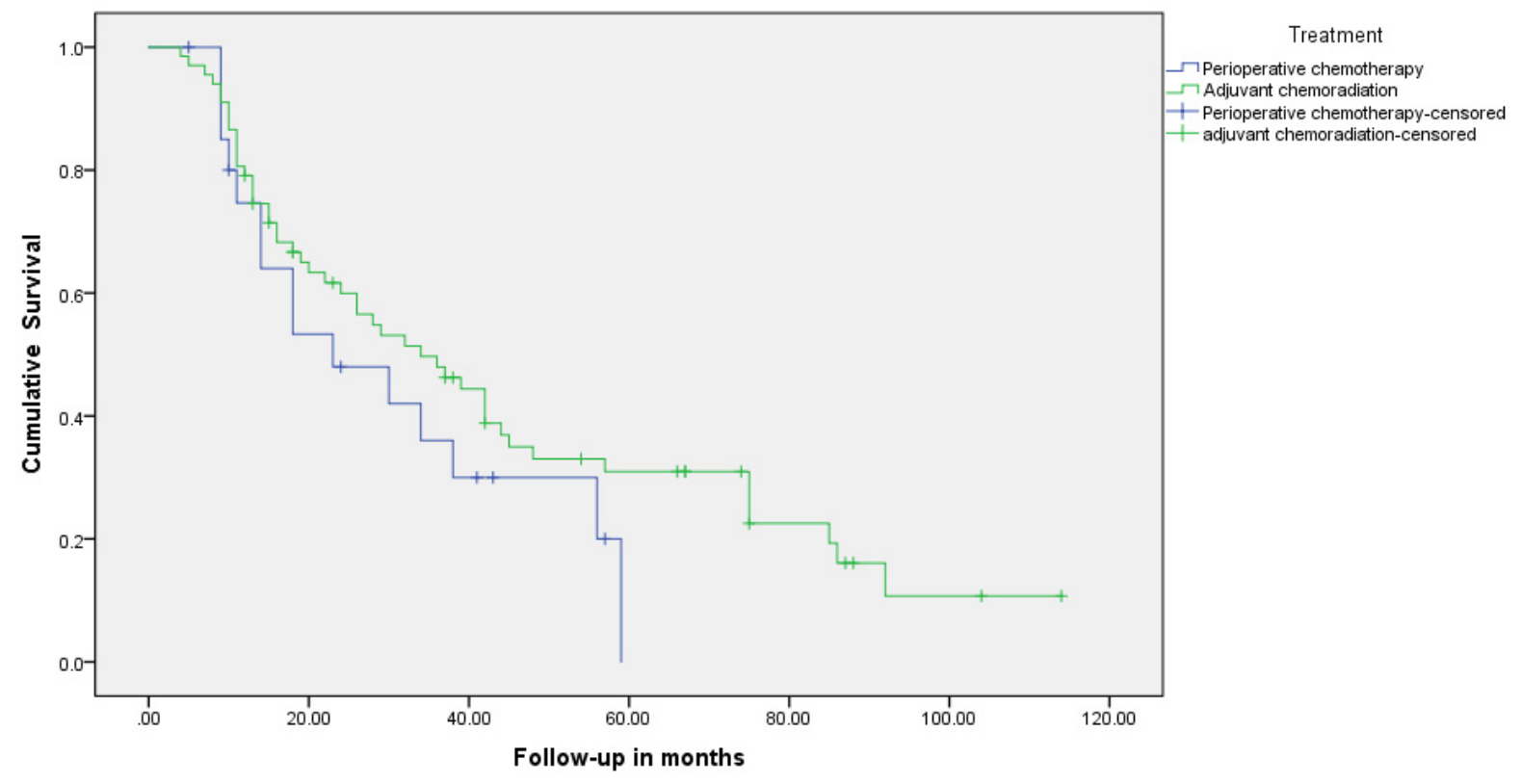

(B)

Figure 2. (A): Kaplan-Meier relapse-free survival curves of two groups: patients who were treated with perioperative chemotherapy compared to those who received adjuvant chemoradiotherapy. (B): Kaplan-Meier overall survival curves of two groups: patients who were treated with perioperative chemotherapy compared to those who received adjuvant chemoradiotherapy.

On multivariate analysis, $\mathrm{T} \geq 3$ tumor HR, 3.45 (95\% CI: 1.39-8.56), NLR > 2.8, HR, 1.85 (1.05-3.25), and positive resection margin, HR, 1.89 (1.06-3.37) were independently correlated with inferior survival (Table 3). PC did not correlate with better survival, HR, 1.39 (0.71-2.68). Tests for interactions between treatment type and other variables were not significant. 
Table 3. Univariate and Multivariate Cox Proportional analyses for relationship between various clinical and pathological variables and mortality. A value greater than 1 suggests an increased risk whereas value lower than 1 suggests decreased risk.

\begin{tabular}{|c|c|c|c|c|}
\hline Variables & HR $(95 \%$ CI) & & & \\
\hline Univariate & & & Multivariate & $p$ \\
\hline Age $\geq 70$ years & $1.01(0.58-1.73)$ & 0.97 & $1.10(0.64-1.88)$ & 0.75 \\
\hline Men & $1.11(0.62-1.97)$ & 0.72 & - & \\
\hline Comorbid illness & $1.16(0.70-1.92)$ & 0.56 & $1.10(0.63-1.78)$ & 0.83 \\
\hline WHO performance status $>0$ & $1.45(0.83-2.53)$ & 0.19 & $1.48(0.80-2.71)$ & 0.21 \\
\hline Secondary cancer & $0.79(0.40-1.57)$ & 0.51 & - & \\
\hline Current smoking & $1.15(0.62-2.12)$ & 0.66 & - & \\
\hline Children & $0.71(0.39-1.27)$ & 0.25 & - & \\
\hline Married & $0.63(0.32-1.25)$ & 0.18 & - & \\
\hline Urban City & $0.97(0.58-1.62)$ & 0.92 & - & \\
\hline $\begin{array}{l}\text { Neutrophil to lymphocyte ratio } \\
\qquad(\text { NLR) }>2.80\end{array}$ & $1.66(1.01-2.75)$ & 0.048 & $1.85(1.05-3.25)$ & 0.034 \\
\hline Node positive & $1.47(0.74-2.89)$ & 0.27 & $1.31(0.63-2.71)$ & 0.48 \\
\hline $\mathrm{T} \geq 3$ & $3.57(1.52-8.40)$ & 0.003 & $3.45(1.39-8.56)$ & 0.008 \\
\hline Positive margin & $2.24(1.32-3.80)$ & 0.003 & $1.89(1.06-3.37)$ & 0.03 \\
\hline Grade 3 & $1.10(0.64-1.89)$ & 0.72 & - & \\
\hline Perioperative therapy & $1.38(0.76-2.50)$ & 0.29 & $1.39(0.71-2.68)$ & 0.33 \\
\hline
\end{tabular}

Tests for interaction between type of treatment and other variables were not significant and are not showing in the table.

Treatment-related toxicity is described in Table 4 . Overall, $34 \%$ of patients required hospital admission, $29 \%$ in the PCR group vs. $52 \%$ in the PC group. The difference did not reach statistical significance. GI toxicity was substantial in both groups. Patients in the PCR group had significantly higher rates of moderate to severe diarrhea ( $40 \%$ in the PCR group vs. $5 \%$ in the PC group). The postoperative complication rates were $57 \%$ in both groups.

Table 4. Treatment toxicities ( $\geq$ grade 2 ) in patients with early stage stomach and GE junction cancers who received adjuvant chemoradiotherapy versus perioperative chemotherapy.

\begin{tabular}{|c|c|c|c|c|}
\hline Variables & $\begin{array}{l}\text { All Patients } \\
N=88(\%)\end{array}$ & $\begin{array}{c}\text { Adjuvant } \\
\text { Chemoradiotherapy Group } \\
\mathrm{N}=67(\%)\end{array}$ & $\begin{array}{c}\text { Peri-Operative } \\
\text { Chemotherapy Group } \\
\text { N }=21(\%)\end{array}$ & $p$ Value \\
\hline Hospital Admission & $30(34)$ & $19(29)$ & $11(52)$ & 0.06 \\
\hline Febrile Neutropenia & $4(5)$ & $4(6)$ & 0 & 0.56 \\
\hline Neutropenia & $11(13)$ & $9(13)$ & $2(10)$ & 1.0 \\
\hline Other infection & $6(7)$ & $6(9)$ & 0 & 0.32 \\
\hline Thrombocytopenia & $1(1)$ & $1(1)$ & $1(5)$ & 0.42 \\
\hline Anemia & $4(5)$ & $3(5)$ & $1(5)$ & 1.0 \\
\hline Nausea & $33(37)$ & $26(39)$ & $7(33)$ & 0.79 \\
\hline Vomiting & $22(25)$ & $18(27)$ & $4(20)$ & 0.57 \\
\hline Diarrhea & $28(32)$ & $27(40)$ & $1(5)$ & 0.002 \\
\hline Neuropathy & $5(6)$ & $3(5)$ & $2(10)$ & 0.58 \\
\hline
\end{tabular}


Table 4. Cont

\begin{tabular}{|c|c|c|c|c|}
\hline Variables & $\begin{array}{l}\text { All Patients } \\
\mathrm{N}=88(\%)\end{array}$ & $\begin{array}{c}\text { Adjuvant } \\
\text { Chemoradiotherapy Group } \\
\mathrm{N}=67(\%)\end{array}$ & $\begin{array}{c}\text { Peri-Operative } \\
\text { Chemotherapy Group } \\
\mathrm{N}=21(\%)\end{array}$ & $p$ Value \\
\hline Thromboembolism & $3(3)$ & $2(3)$ & $1(5)$ & 0.56 \\
\hline Mucositis & $31(35)$ & $27(40)$ & $4(19)$ & 0.11 \\
\hline Fatigue & $17(19)$ & $15(22)$ & $2(10)$ & 0.34 \\
\hline Rash & $6(7)$ & $6(9)$ & 0 & 0.32 \\
\hline Others & $37(42)$ & $29(43)$ & $8(38)$ & 0.80 \\
\hline Post-operative complications & $50(57)$ & $38(57)$ & $12(57)$ & 1.0 \\
\hline Wound infection & $7(8)$ & $6(9)$ & $1(5)$ & 1.0 \\
\hline Other infection & $14(16)$ & $8(12)$ & $6(29)$ & 0.08 \\
\hline Leakage & $14(16)$ & $9(13)$ & $5(24)$ & 0.30 \\
\hline Thromboembolism & $1(1)$ & 0 & $1(5)$ & 0.23 \\
\hline Cardiovascular events & $6(7)$ & $4(6)$ & $2(10)$ & 0.62 \\
\hline
\end{tabular}

\section{Discussion}

It has been clear for some time that surgery alone is inadequate treatment for stomach cancer. The initial efforts to improve the outcome of surgery alone centered on the INT0116 trial with adjuvant chemotherapy and radiation. This trial was widely adopted in North America, including Saskatchewan, and at the start of the study period, it was the most common approach for surgically resectable stomach cancers. As the results of the MAGIC trial were reported and later supported by other PC trials, this approach was more widely adopted and gained acceptance in the surgical community [18]. An analysis of the U.S. National Cancer database showed an increase in the use of PC from $7.5 \%$ to $46 \%$ between 2006 and 2013 [19]. Given that this shift was happening through the later part of our study, it is not surprising that $76 \%$ of the study population received PCR as per the INT-0116 protocol.

We noted a high discordance between clinical and pathological staging. Only 7\% of the patients were classified as having stage III disease based on preoperative imaging analysis, but this number rose to $52 \%$ upon review of surgical pathology. In the early part of the study, CT scans were the main imaging modality for most patients. Later, CT-PET scans were routinely used for staging purposes. Even though CT-PET scans are more effective than CT scans for stomach cancer staging, their sensitivity is limited for nodal staging [20].

Although there is limited data on the comparison between the PC approach and adjuvant chemoradiotherapy, one analysis reported by Jabo et al. that involved 2146 patients showed improved outcomes with PCR over PC [21]. Our results also favor PCR over PC, but these results are statistically insignificant. Our analysis is limited by the low numbers of patients, especially for the PC group. A much larger analysis of the U.S. National Cancer database of over 9000 patients showed no difference between PC and PCR [19]. There was no difference in survival between PC and PCR. Surprisingly, over $40 \%$ of patients only had surgery and did not receive additional therapy. This number stayed fairly constant between 2006 and 2013. This study also highlights the need for multidisciplinary discussion in the management of stomach cancer for optimal treatment.

PC has also evolved and improved over time and better results are seen with the FLOT, the newer chemotherapy regimen [18]. In our study, the majority of patients $(66 \%)$ received the ECF (epirubicin, a platinum compound and 5FU) chemotherapy regimen. Only one patient received FLOT. All of the patients who were designated to receive PC went on to receive all planned preoperative chemotherapy cycles. Even in the postoperative setting, 
$66 \%$ of patients were able to receive the planned chemotherapy. This number is close to the original MAGIC trial where $58 \%$ of the subjects assigned to postoperative chemotherapy actually received it. This may be in part due to vigorous patient selection, with $98 \%$ of the patients being ECOG 0 or 1 . This is something not commonly seen outside the context of clinical trials and may be partly explained by the fact that all patients who were not candidates for chemotherapy were excluded.

The median survival in the INT-0116 trial was 36 months for the PCR group. This cannot be directly compared to the MAGIC trial, as they had different entry points into the trial. This number is very similar to the 38 months (24.6-51.4) seen in our trial. The median survival in the ECF arm in the more recent FLOT study was 35 months. This is better than the OS of 30 months (14.3-45.7) in the PC group. Patients treated with a docetaxel-based FLOT regimen had a median OS of 50 months that has shifted the pendulum in favor of PC in the last few years. Of note, we did not collect treatment information for recurrent disease that could potentially affect survival.

Multivariate analysis also suggested worse outcome with $\mathrm{T} \geq 3$ and margin positive disease but not with lymph node status. All three of these outcomes have been previously correlated with poorer survival [22,23]. It is likely that the lymph node status was affected by the high rate $(>80 \%)$ of node positive disease in the entire group, as it impacted the statistical significance of this variable.

Toxicities were similar in both groups. However, patients in the PC group numerically had a high rate of hospital admission. The main toxicities were hematological and gastrointestinal. These two side effects feature prominently in the original INT-0116 trial, as well as the MAGIC trial. Significant postoperative toxicities (57\%) in both groups were seen in our study, but PC did not add to additional toxicity at the time of surgery. This was also appreciated in the MAGIC trial where the toxicity in the preoperative chemotherapy group was similar to the surgery alone group (45\% in both groups) [5].

Of significant importance, a high baseline NLR was also associated with a poor outcome in the multivariate analysis. This has previously been described as an independent variable in multiple cancers, including gastric cancer as described by Zhang et al. [24]. In this study three-fourths of the patients underwent surgical resection, and a low NLR was associated with an OS benefit (36.0 months vs. 20.5 months, $p<0.001)$. The NLR can be used as an additional metric in risk stratification of newly diagnosed patients with gastric cancer. This may be particularly true for patients who are borderline candidates for surgical resection.

Both treatments are thus feasible and part of international guidelines, although the recent trend is moving towards PC despite there being no randomized trials clearly outlining the superiority of this approach $[25,26]$. PC does allow systemic disease to be addressed earlier and spares the morbidity of gastrectomy in patients who were destined to do poorly. Given the impressive survival data with FLOT regimen it has established itself as the new standard of care for patients who are fit to receive combination therapy. FLOT basedperioperative therapy has also been adopted as the preferred approach in Saskatchewan for patients with early stomach cancer who are candidates for combination chemotherapy. The role of radiation therapy with FLOT regimen is currently not known and will be determined by future trials. Current clinical trials in early stage stomach cancer are evaluating the efficacy of immunotherapy in combination with chemotherapy and combination of immunotherapy and chemotherapy may become a new standard of care [27].

In conclusion, this well-designed population-based cohort study using individual patient data suggests that both PC and PCR remain feasible approaches for patients in the real-world setting. 
Author Contributions: Conceptualization, A.Z., K.H., O.A., D.-A.D., B.B., D.G. and S.A.; Data curation, A.K and C.D.; Formal analysis, S.A.; Funding acquisition, A.Z. and S.A.; Investigation, A.Z. and S.A.; Methodology, A.Z., K.H., O.A., D.-A.D. and S.A.; Project administration, A.Z., A.K., C.D. and S.A.; Software, S.A.; Supervision, A.Z. and S.A.; Writing-original draft, A.Z.; Writing-review \& editing, A.Z., A.K., C.D., K.H., O.A., D.-A.D., B.B., D.G. and S.A. All authors have read and agreed to the published version of the manuscript.

Funding: The study was funded by Saskatchewan Cancer Agency Research grant 2019-2020 (421419).

Institutional Review Board Statement: The study was approved by the University of Saskatchewan Ethics Board “Bio-261 The University of Saskatchewan Biomedical Research Ethics Board (Bio-REB) has reviewed the above-named research study. The study was found to be acceptable on scientific and ethical grounds. The principal investigator has the responsibility for any other administrative or regulatory approvals that may pertain to this research study, and for ensuring that the authorized research is carried out according to governing law. This approval is valid for the specified period provided there is no change to the approved protocol or consent process".

Informed Consent Statement: All procedures performed in studies involving human participants were in accordance with the ethical standards of the institutional and/or national research committee and with the 1964 Helsinki declaration and its later amendments or comparable ethical standards. The University of Saskatchewan's Biomedical Research Ethic Board approved the study and waived informed consent.

Data Availability Statement: Due to privacy and confidentially data is not available. Part of the data was presented at the European Society of Medical Oncology (ESMO) Annual virtual meeting in September, 2020.

Acknowledgments: We thank Saskatchewan Cancer Agency and its Data Access Committee for providing support for this research.

Conflicts of Interest: No author has any conflict of interest to report.

\section{References}

1. Siegel, R.; Naishadham, D.; Jemal, A. Cancer statistics, 2013. CA Cancer J. Clin. 2013, 63, 11-30. [CrossRef] [PubMed]

2. Jemal, A.; Bray, F.; Center, M.M.; Ferlay, J.; Ward, E.; Forman, D. Global cancer statistics. CA Cancer J. Clin. 2011, 61, 69-90. [CrossRef] [PubMed]

3. Ferlay, J.; Shin, H.; Bray, F.; Forman, D.; Mathers, C.; Parkin, D. GLOBOCAN 2008 v2.0, Cancer Incidence and Mortality Worldwide: IARC Cancer Base No. 10; International Agency Research Cancer: Lyon, France, 2010.

4. Macdonald, J.S.; Smalley, S.R.; Benedetti, J.; Hundahl, S.A.; Estes, N.C.; Stemmermann, G.N.; Haller, D.G.; Ajani, A.J.; Gunderson, L.L.; Jessup, J.M.; et al. Chemoradiotherapy after surgery compared with surgery alone for adenocarcinoma of the stomach or gastroesophageal junction. N. Engl. J. Med. 2001, 345, 725-730. [CrossRef] [PubMed]

5. Cunningham, D.; Allum, W.H.; Stenning, S.P.; Thompson, J.N.; Van de Velde, C.J.H.; Nicolson, M.; Scarffe, J.H.; Lofts, F.J.; Falk, S.J.; Iveson, T.J.; et al. Perioperative chemotherapy versus surgery alone for resectable gastroesophageal cancer. N. Engl. J. Med. 2006, 355, 11-20. [CrossRef]

6. $\quad$ Boige, V.; Pignon, J.-P.; Saint-Aubert, B.; Lasser, P.; Conroy, T.; Bouché, O.; Segol, P.; Bedenne, L.; Rougier, P.; Ychou, M. Final results of a randomized trial comparing preoperative 5-fluorouracil/cisplatin to surgery alone in adenocarcinoma of stomach and lower esophagus (ASLE): FNLCC ACCORD07-FFCD 9703 trial (abstract). J. Clin. Oncol. 2007, 25, 200s. [CrossRef]

7. Nio, Y.; Koike, M.; Omori, H.; Hashimoto, K.; Itakura, M.; Yano, S.; Higami, T.; Maruyama, R. A randomized consent design trial of neoadjuvant chemotherapy with tegafur plus uracil (UFT) for gastric cancer-A single institute study. Anticancer Res. 2004, 24, 1879-1887.

8. Schuhmacher, C.; Gretschel, S.; Lordick, F.; Reichardt, P.; Hohenberger, W.; Eisenberger, C.F.; Haag, C.; Mauer, M.E.; Hasan, B.; Welch, J.; et al. Neoadjuvant chemotherapy compared with surgery alone for locally advanced cancer of the stomach and cardia: European Organisation for Research and Treatment of Cancer randomized trial 40954. J. Clin. Oncol. 2010, 28, 5210-5218. [CrossRef]

9. Xiong, B.H.; Cheng, Y.; Ma, L.; Zhang, C.Q. An updated meta-analysis of randomized controlled trial assessing the effect of neoadjuvant chemotherapy in advanced gastric cancer. Cancer Investig. 2014, 32, 272-284. [CrossRef]

10. Bamias, A.; Karina, M.; Papakostas, P.; Kostopoulos, I.; Bobos, M.; Vourli, G.; Samantas, E.; Christodoulou, C.; Pentheroudakis, G.; Pectasides, D.; et al. A randomized phase III study of adjuvant platinum/docetaxel chemotherapy with or without radiation therapy in patients with gastric cancer. Cancer Chemother. Pharmacol. 2010, 65, 1009-1021. [CrossRef]

11. Bang, Y.J.; Kim, Y.W.; Yang, H.K.; Chung, H.C.; Park, Y.-K.; Lee, K.H.; Lee, K.-W.; Kim, Y.H.; Noh, S.-I.; Cho, J.Y.; et al. Adjuvant capecitabine and oxaliplatin for gastric cancer after D2 gastrectomy (CLASSIC): A phase 3 open-label, randomised controlled trial. Lancet 2012, 379, 315-321. [CrossRef] 
12. Kim, T.H.; Park, S.R.; Ryu, K.W.; Lim, D.H.; Hong, M.E.; Kim, K.-M.; Sohn, I.; Jung, S.H.; Choi, M.G.; Lee, J.H.; et al. Phase 3 trial of postoperative chemotherapy alone versus chemoradiation therapy in stage III-IV gastric cancer treated with R0 gastrectomy and D2 lymph node dissection. Int. J. Radiat. Oncol. Biol. Phys. 2012, 84, e585. [CrossRef]

13. Park, S.H.; Sohn, T.S.; Lee, J.; Lim, D.H.; Hong, M.E.; Kim, K.-M.; Sohn, I.; Jung, S.H.; Choi, M.G.; Lee, J.H.; et al. Phase III trial to compare adjuvant chemotherapy with capecitabine and cisplatin versus concurrent chemoradiotherapy in gastric cancer: Final report of the adjuvant chemoradiotherapy in stomach tumors trial, including survival and subset analyses. J. Clin. Oncol. 2015, 33, 3130-3136. [CrossRef]

14. Smalley, S.R.; Benedetti, J.K.; Haller, D.G.; Hundahl, S.A.; Estes, N.C.; Ajani, J.A.; Gunderson, L.L.; Goldman, B.; Martenson, J.A.; Jessup, J.M.; et al. Updated analysis of SWOG-directed intergroup study 0116: A phase III trial of adjuvant radiochemotherapy versus observation after curative gastric cancer resection. J. Clin. Oncol. 2012, 30, 2327-2333. [CrossRef]

15. GASTRIC Group; Paoletti, X.; Oba, K.; Burzykowski, T.; Michiels, S.; Ohashi, Y.; Pignon, J.-P.; Rougier, P.; Sakamoto, J.; Sargent, D.; et al. Benefit of adjuvant chemotherapy for resectable gastric cancer: A meta-analysis. JAMA 2010, 303, 1729-1737. [PubMed]

16. Dai, Q.; Jiang, L.; Lin, R.J.; Wei, K.K.; Gan, L.L.; Deng, C.H.; Guan, Q.L. Adjuvant chemoradiotherapy versus chemotherapy for gastric cancer: A meta-analysis of randomized controlled trials. J. Surg. Oncol. 2015, 111, 277-284. [CrossRef]

17. Fitzgerald, T.L.; Efird, J.T.; Bellamy, N.; Russo, S.M.; Jindal, C.; Mosquera, C.; Holliday, E.G.; Biswas, T. Perioperative chemotherapy versus postoperative chemoradiotherapy in patients with resectable gastric/gastroesophageal junction adenocarcinomas: A survival analysis of 5058 patients. Cancer 2017, 123, 2909-2917. [CrossRef]

18. Al-Batran, S.-E.; Homann, N.; Pauligk, C.; O'Goetze, T.; Meiler, J.; Kasper, S.; Kopp, H.-G.; Mayer, F.; Haag, G.M.; Luley, K.; et al. Perioperative chemotherapy with fluorouracil plus leucovorin, oxaliplatin, and docetaxel versus fluorouracil or capecitabine plus cisplatin and epirubicin for locally advanced, resectable gastric or gastro-oesophageal junction adenocarcinoma (FLOT4): A randomised, phase 2/3 trial. Lancet 2019, 393, 1948-1957. [CrossRef]

19. Jayanathan, M.; Ryan, P.; Molacek, E.N.; Fluck, M.; Hunsinger, M.; Wild, J.; Arora, T.K.; Shabahang, M.M.; Franko, J.; Blansfield, J.A.; et al. MAGIC versus MacDonald treatment regimens for gastric cancer: Trends and predictors of multimodal therapy for gastric cancer using the National Cancer Database. Am. J. Surg. 2020, 219, 129-135, ISSN 0002-9610. [CrossRef]

20. Findlay, J.M.; Antonowicz, S.; Segaran, A.; El Kafsi, J.; Zhang, A.; Bradley, K.M.; Gillies, R.S.; Maynard, N.D.; Middleton, M.R. Routinely staging gastric cancer with ${ }^{18}$ F-FDG PET-CT detects additional metastases and predicts early recurrence and death after surgery. Eur. Radiol. 2019, 29, 2490-2498. [CrossRef] [PubMed]

21. Jabo, B.; Selleck, M.J.; Morgan, J.W.; Lum, S.S.; Bahjri, K.A.; Aljehani, M.; Garberoglio, C.A.; Reeves, M.E.; Namm, J.P.; Solomon, N.L.; et al. Comparison of perioperative chemotherapy with adjuvant chemoradiotherapy for resectable gastric cancer: Findings from a population-based study. J. Gastrointest. Oncol. 2018, 9, 35-45. [CrossRef] [PubMed]

22. Orman, S.; Cayci, H.M. Gastric cancer: Factors affecting survival. Acta Chir. Belg. 2019, 119, 24-30. [CrossRef]

23. Cordero-García, E.; Ramos-Esquivel, A.; Alpízar-Alpízar, W. Predictors of overall survival after surgery in gastric cancer patients from a Latin-American country. J. Gastrointest. Oncol. 2018, 9, 64-72. [CrossRef] [PubMed]

24. Zhang, Y.; Lu, J.J.; Du, Y.P.; Feng, C.X.; Wang, L.Q.; Chen, M.B. Prognostic value of neutrophil-to-lymphocyte ratio and platelet-to-lymphocyte ratio in gastric cancer. Medicine 2018, 97, e0144. [CrossRef] [PubMed]

25. Smyth, E.C.; Verheij, M.; Allum, W.; Cunningham, D.; Cervantes, A.; Arnold, D. Gastric cancer: ESMO Clinical Practice Guidelines for diagnosis, treatment and follow-up. Ann. Oncol. 2016, 27, v38-v49. [CrossRef] [PubMed]

26. Available online: https://www.nccn.org/professionals/physician_gls/pdf/gastric.pdf (accessed on 12 March 2021).

27. Bang, Y.-J.; Van Cutsem, E.; Fuchs, C.S.; Ohtsu, A.; Tabernero, J.; Ilson, D.H.; Hyung, W.J.; Strong, V.E.; Goetze, T.O.; Yoshikawa, T.; et al. KEYNOTE-585: Phase 3 study of chemotherapy (chemo) + pembrolizumab (pembro) vs chemo + placebo as neoadjuvant/adjuvant treatment for patients (pts) with gastric or gastroesophageal junction (G/GEJ) cancer. J. Clin. Oncol. 2018, 36, TPS4136. [CrossRef] 